\title{
Tecnologia eletrônica e letramento digital: um inventário da pesquisa nascente no Brasil ${ }^{1}$
}

Iúta Lerche Vieira

Universidade Estadual do Ceará

Neste estudo analisamos títulos/resumos de trabalhos apresentados em 5 eventos científicos brasileiros de diferentes níveis, de 2000 a 2001, com o objetivo de mapear os estudos nascentes no país, envolvendo texto eletrônico e letramento digital. As questões centrais do levantamento foram: O que está sendo investigado nesses estudos? Como a tecnologia do computador está sendo abordada na pesquisa lingüística? Os dados oferecem uma visão do desenvolvimento da pesquisa em tecnologia/letramento no Brasil, no período assinalado, em relação a: representatividade e produtividade desse campo de estudo nos eventos analisados e no corpus de trabalhos sobre a temática; foco das investigações, problemas de pesquisa (em especial os referentes ao texto eletrônico, uso do computador, formas de ensino virtual) e abordagens priorizadas; pesquisadores/instituições atuantes nessa nova área de investigação.

In this study, we analyze titles/summaries of works presented in 5 Brazilian scientific events at different levels, from 2000 through 2001, with the objective of tracking new studies in the country covering electronic text and digital literacy. Core survey issues included: What are such studies investigating? How is computer technology addressed at linguistic surveys? Data provide a view of the development of the linguistic research in literacy/technology in Brazil, over the period mentioned above, in relation to: representativeness and productivity of this field of study in the analyzed events and in the corpus of works on the theme; the investigation focus, research problems (in particular those related to electronic text, computer use, methods of virtual teaching) and prioritized approaches; researches/institutions involved in this new investigation area.

${ }^{1}$ Trabalho apresentado na 54a Reunião Anual da SBPC, Goiânia, 07 a 12 /07/ 2002, cuja temática central foi "Ciência e Universidade rompendo fronteiras" e na XIX Jornada Nacional de Estudos Lingüísticos (GELNE), Fortaleza, 04 a 06/ 09/2002. Agradeço a colaboração de Carmem Sílvia de Carvalho Rego pelo tratamento gráfico das informações e pela ajuda, como bolsista de Iniciação Científica, no levantamento dos dados. 


\section{Introdução}

A Internet e demais formas de tecnologia da informação/comunicação estão redefinindo a natureza do letramento, ampliando e diversificando o acesso, uso e divulgação da linguagem escrita. Processadores eletrônicos de texto, impressoras domésticas, e-mails, salas de bate-papo (chats), listas de discussão, cursos não-presenciais, bibliotecas virtuais, leitura, pesquisa ou compras na Web, tudo isso ilustra o novo ambiente em que se move o leitor/redator, da tela de seu computador para o instantâneo cyberespaço. Trata-se de um cenário múltiplo e diversificado que é preciso conhecer.

A idéia de um letramento básico centrado em "habilidades mínimas para ler/escrever numa determinada linguagem e/ou modo de pensar sobre usos da leitura e da escrita na vida diária" (HODGES, 1999, p. 19) hoje cede lugar a um continuum dinâmico de novos e vários letramentos, socialmente construídos, dentre os quais o letramento digital, foco do presente estudo. Trata-se das competências necessárias para realizar uma variedade de tarefas relativas à linguagem e uso do computador (SEMALI, 2003). A expressão "letramento digital" aqui está sendo empregada tanto na perspectiva de meio, como de fim: quer como uso de dados em suporte eletrônico na pesquisa lingüística, para examinar questões correntes, quer como novas situações lingüístico-comunicativas na Internet, por investigar.

Os chamados "novos letramentos" (NLs) surgem de necessidades emergentes na era "pós-tipográfica", com a comunicação visual e eletrônica (SEMALI, 2003), chegando a ser considerados o tema mais importante na agenda educacional mundial (LEU, 2002). Envolvem novas formas de conhecimento estratégico ou esquemas para lidar com tecnologias na vida diária e habilidade para ler/produzir textos típicos da era da multimídia e da informação. Significa dizer que, ao lado dos textos impressos, da exigência de saber ler criticamente, recuperar e processar informação, agora também se faz necessário saber lidar com imagens e representações gráficas.

Letramento tem se tornado um termo "dêitico" (LEU, 2000), ou seja, muda de significado dependendo do momento ou do local (âmbito) no qual é proferido. Na verdade, é um conceito sujeito a reconceptualizações constantes. As rápidas transformações tecnológicas 
fazem com que as formas de letramento se (re)definam em função de seu contexto de uso, daí uma certa dificuldade em propor definições permanentes. Outro aspecto é a superposição de aspectos incluídos em vários letramentos afins, como por exemplo entre letramento do computador, da mídia, da informação e letramento visual. Para definições mais abrangentes, é preciso adotar uma perspectiva crítica, observando como cada forma de letramento gera sentidos e como seus especialistas os percebem.

Do ponto de vista da pesquisa, as novas tecnologias da informação e suas relações com as formas de letramento constituem campo novo de investigação, com inúmeros problemas a explorar (KAMIL, INTRATOR e KIM, 2000). No dizer de Crystal (2002), a cyberfala é uma língua em transição, sendo prioritário investigar as situações comunicativas na Internet. Contudo, ainda não há uma tradição de pesquisa em letramento/tecnologia, especialmente pela velocidade e complexidade crescentes com que a tecnologia da informação vem mudando. Tal lacuna é inerente à própria natureza da relação tecnologia/letramento, identificada globalmente e não apenas em nível de Brasil. Registre-se, ainda, que as tecnologias de computador têm uma história recente, chegando quando muito a quatro décadas (KAMIL et al., op. cit.).

Integrando o projeto Da escrita à mão ao e-texto: Estudos sobre tecnologia \& novos letramentos, ${ }^{2}$ o presente trabalho focaliza o tratamento dessa problemática no âmbito da pesquisa lingüistica, identificando como o texto eletrônico e respectivas práticas de letramento estão sendo abordados no Brasil. Procura explorar os setores de estudo mais relevantes no período 2000/2001, buscando identificar que áreas de estudos lingüísticos são priorizadas, que tipo de investigações estão sendo desenvolvidas no país, como vem se distribuindo a atividade de pesquisa e se há trocas interinstitucionais nesse novo campo de investigação.

\footnotetext{
2 Projeto em desenvolvimento na Universidade Estadual do Ceará, com duração prevista até 2005, coordenado pela autora, com apoio de 3 bolsistas de Iniciação Científica (CNPq e FUNCAP). O referido projeto investiga dimensões novas do ler/escrever com a introdução da tecnologia do computador, em diferentes contextos.
} 


\section{Metodologia}

Trata-se de um estudo exploratório de caráter descritivo/ quantitativo, cujo corpus de análise são títulos e resumos de trabalhos apresentados em 5 congressos sobre estudos teóricos e/ou aplicados da linguagem, realizados no Brasil no período em questão.

Para obter uma visão representativa da problemática em foco, foram selecionados eventos científicos de diferentes níveis (sendo um internacional, três nacionais e um regional), realizados por entidades representativas dos estudos lingüísticos no país, em instituições de reconhecida tradição acadêmica e científica, assim denominados:

Evento A - $\quad$ IV Congresso Nacional de Lingüística e Filologia. Rio de Janeiro, UERJ, 28/08 a01/09/2000;

Evento B - $\quad$ XVIII Jornada de Estudos Lingüisticos do Nordeste. Salvador, UFBA, 03 a 06/09/2000;

Evento C - $\quad$ II Congresso Internacional da Associação Brasileira de Lingüística. Fortaleza, UFC, 13 a 16/03/2001;

Evento D - $\quad$ I Simpósio Nacional Discurso, Identidade e Sociedade. Rio de Janeiro, PUC-Rio, 17 a 19/05/2001;

Evento E - $\quad$ VI Congresso Brasileiro de Lingüística Aplicada - A Linguagem como Prática Social (VI CBLA). Belo Horizonte, UFMG, 07 a 11/ 10/2001.

Num universo de 2538 trabalhos (apresentados nesses 5 congressos) foram identificados todos os trabalhos envolvendo letramento/tecnologia (76), tomados como corpus de análise do presente estudo, conforme mostra o gráfico 1 :

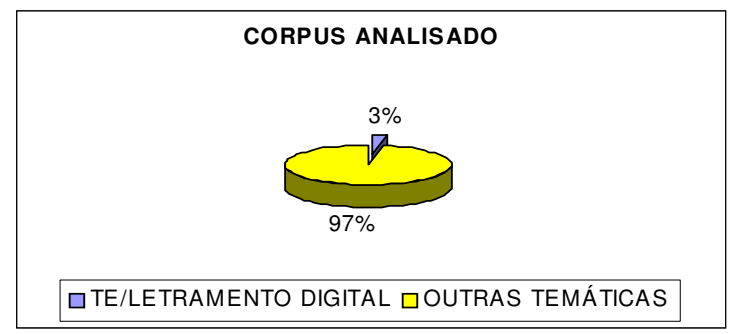

Gráfico 1 - Corpus analisado

Os dados foram codificados e assim categorizados:

a) Levantamento 1 - título, autoria, instituição de origem do pesquisador e modalidade de apresentação do trabalho por gêneros acadêmicos, 
b) Levantamento 2 - objeto estudado, foco do trabalho, objetivo, metodologia, língua-alvo e área de estudo priorizada.

\section{Resultados}

\section{Desenvolvimento da pesquisa lingüística em letramento e tecnologia}

Iniciamos examinando a representatividade dos estudos sobre letramento/tecnologia digital na pesquisa lingüística no Brasil, no período 2000/2001. Nesse sentido, indagamos: a) Como se apresenta a pesquisa lingüística em letramento e tecnologia no Brasil? b) Há tendência de crescimento na área? Em que âmbito?

O quadro seguinte dá uma idéia geral dessas questões, situando os dados em termos quantitativos:

QUADRO 1 - Distribuição dos trabalhos sobre a temática texto eletrônico (TE) e letramento digital (LD) nos eventos científicos da amostra

\begin{tabular}{|c|c|c|c|c|c|c|}
\hline $\begin{array}{c}\text { Eventos } \\
\text { em ordem } \\
\text { cronológica }\end{array}$ & $\begin{array}{c}\text { Âmbito } \\
\text { do } \\
\text { evento }\end{array}$ & $\begin{array}{c}\text { Total de } \\
\text { trabalhos } \\
\mathrm{p} / \text { evento }\end{array}$ & $\begin{array}{c}\text { Trabalhos } \\
\mathrm{s} / \text { o tema } \\
\mathrm{p} / \text { evento }\end{array}$ & $\begin{array}{c}\% \text { trab. } \\
\mathrm{s} / \text { o tema } \\
\text { em cada } \\
\text { evento }\end{array}$ & $\begin{array}{c}\text { Tamanho } \\
\text { do evento } \\
\text { trabs.evento } \\
\text { total trab. }\end{array}$ & $\begin{array}{c}\text { Represen- } \\
\text { tatividade } \\
\text { em relação } \\
\text { ao tema }\end{array}$ \\
\hline A & Nacional & 169 & 5 & $3 \%$ & $7 \%\left(5^{\circ}\right)$ & $6 \%\left(5^{\circ}\right)$ \\
B & Regional & 671 & 6 & $1 \%$ & $6 \%\left(2^{\circ}\right)$ & $8 \%\left(4^{\circ}\right)$ \\
C & Internac. & 828 & 18 & $2 \%$ & $33 \%\left(1^{\circ}\right)$ & $25 \%\left(2^{\circ}\right)$ \\
D & Nacional & 253 & 10 & $4 \%$ & $10 \%\left(4^{\circ}\right)$ & $13 \%\left(3^{\circ}\right)$ \\
E & Nacional & 617 & 37 & $6 \%$ & $24 \%\left(3^{\circ}\right)$ & $48 \%(1)$ \\
Total & $\mathbf{5}$ & $\mathbf{2 5 3 8}$ & $\mathbf{7 6}$ & $\mathbf{1 6 \%}$ & $\mathbf{1 0 0 \%}$ & $\mathbf{1 0 0 \%}$ \\
\hline
\end{tabular}

LEGENDA/Eventos: A = IV Congresso Nacional de Lingüística e Filologia Rio de Janeiro/ UERJ, 28/08 a 01/09/2000; B= XVIII Jornada de Estudos Lingüisticos do Nordeste (GELNE), Salvador/ UFBA, 03 a 06/09/2000; C= II Congresso Internacional da Associação Brasileira de Lingüística (ABRALIN), Fortaleza/UFC, 13 a 16/03/2001; D= I Simpósio Nacional "Discurso, Identidade e Sociedade", Rio de Janeiro/ PUC-Rio e UFRJ, 17 a 19/05/2001; $\mathbf{E}=$ VI Congresso Brasileiro de Lingüística Aplicada - A Linguagem como Prática Social (VI CBLA), Belo Horizonte/UFMG, 07 a 11/10/2001.

No geral, verificamos que a proporção de trabalhos sobre a temática em estudo ainda é pequena no Brasil, ou seja, apenas 3\%. Contudo, há um discreto, mas contínuo, crescimento de um evento para outro, configurando uma tendência de expansão na área. Considerando que os eventos 
científicos estão dispostos no Quadro 1 em ordem cronológica, verificamos que, à cada novo evento, aumenta o número desses trabalhos (ver colunas 3 e 5 com dados de freqüência absoluta e relativa), especialmente os nacionais. A coluna 7 confirma esse dado, mostrando como os eventos mais recentes são mais representativos no tratamento da temática TE/ LD. A única inversão nessa ordem (verificada entre o $2^{\circ}$ e o $3^{\circ}$ eventos) poderia ser explicada pelo fato de o evento $C$ ser um evento internacional, reunindo trabalhos de outros países onde a pesquisa em letramento tecnológico está bem mais avançada, além de constituir o maior entre os 5 eventos estudados. Quanto ao o evento D, foi mais seletivo, tratando de temática mais específica que os demais. Dessa forma, podemos dizer que a tendência é aumentar o número de investigações na área, independente do tamanho do evento. O gráfico seguinte representa essa expansão do tema nos eventos analisados:

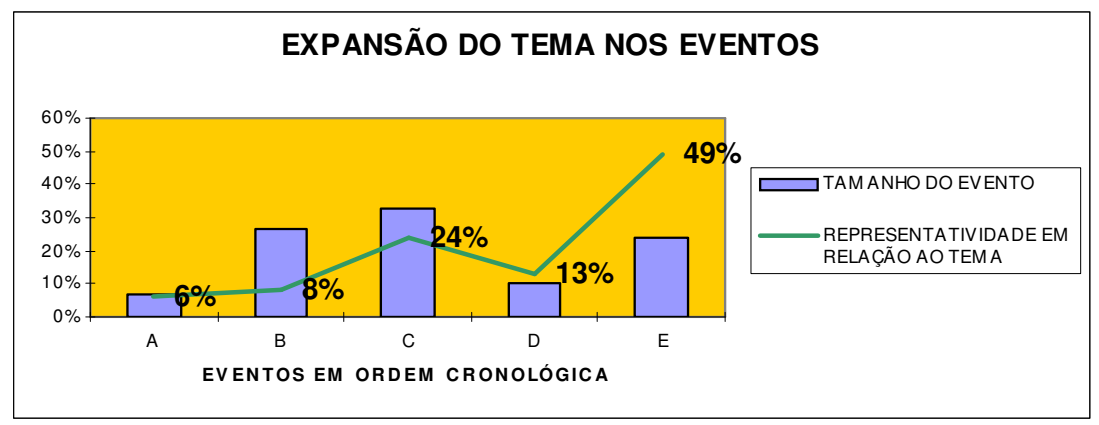

Gráfico 2 - Expansão do tema nos eventos

\section{Tendências dos estudos sobre letramento digital 2000/2001}

A partir da análise dos títulos/resumos dos trabalhos na área de letramento/tecnologia digital identificados na amostra, buscamos obter respostas às seguintes questões: o que está sendo investigado? (a seguir detalharemos também os assuntos priorizados dentro de cada área); como a tecnologia do computador está sendo abordada na pesquisa lingüística?:

Como um meio novo para veicular experiências e dados lingüísticos em áreas já conhecidas? (meio desconhecido + informações conhecidas);

Como um fim em si mesmo, centralizando informações novas? (meio desconhecido + informações desconhecidas); 
Ou ainda, como ambos? Um meio novo, voltado em parte para conhecimentos existentes, mas podendo produzir transformações e implicando repensar questões numa outra ordem de produção do conhecimento? (meio desconhecido + informações não exatamente novas, mas "diferentes").

$\mathrm{E}$, finalmente, em termos de língua-alvo (materna ou estrangeira): qual a prioridade dos estudos?

Comecemos pelo levantamento temático do corpus, onde estão listados e codificados os trabalhos que foram analisados:

QUADRO 2 - Levantamento dos trabalhos por títulos, áreas de estudo e língua-alvo

\begin{tabular}{|c|c|c|}
\hline \multicolumn{3}{|c|}{$\begin{array}{l}\text { GRUPO TEMÁTICO 1: Ensino/Aprendizagem de Línguas Mediado pelo } \\
\text { Computador ( } 20 \text { trabalhos }=26 \% \text { ) }\end{array}$} \\
\hline CÓDIGO & TÍTULO (referência bibliográfica) & ÁREA - LM, LE / conteúdo \\
\hline A4 & $\begin{array}{l}\text { Pós-graduação a distância pela } \\
\text { Internet em Filologia (2000, p. } 74)\end{array}$ & Filologia estudo da língua na literatura \\
\hline C13 & $\begin{array}{l}\text { Novas tecnologias } \\
\text { comunicacionais e educação } \\
\text { continuada }(2001, \text { p. } 102)\end{array}$ & $\begin{array}{l}\text { LM } \\
\text { conteúdo inter e multidisciplinar - } \\
\text { "Novas tecnologias comunicacionais } \\
\text { e educação continuada" }\end{array}$ \\
\hline C14 & $\begin{array}{l}\text { Oprocesso interativo no ensino } \\
\text { de lingua portuguesa na WEB } \\
(2001, \text { p. } 105)\end{array}$ & $\begin{array}{l}\text { LM } \\
\text { novas posssiblidades para o enino de } \\
\text { LP na Web }\end{array}$ \\
\hline C16 & $\begin{array}{l}\text { Interação em aulas pela Internet- } \\
\text { fala ou escrita? (2001, p. 122) }\end{array}$ & $\begin{array}{l}\text { LM } \\
\text { fala/escrita, abertura/fechamento } \\
\text { do tópico discursivo }\end{array}$ \\
\hline C19 & $\begin{array}{l}\text { Linguagem e interação no ensino } \\
\text { de lingua portuguesa via Internet } \\
(2001, \text { p. 168) }\end{array}$ & $\begin{array}{l}\text { LM } \\
\text { curso de redação para vestibulandos } \\
\text { via Internet, no projeto "Pesquisa em } \\
\text { Português para fins específicos - PUC/SP" }\end{array}$ \\
\hline E41 & $\begin{array}{l}\text { Call by design: language learning } \\
\text { through projects and technology- } \\
\text { mediated environments (2001, p.31) }\end{array}$ & $\begin{array}{l}\text { LE } \\
\text { tipos de ambientes de ensino da } \\
\text { linguagem com mediação do } \\
\text { computador }\end{array}$ \\
\hline $\mathrm{E} 43$ & $\begin{array}{l}\text { INGREDE e sua metáfora } \\
(2001, \text { p. } 34)\end{array}$ & $\begin{array}{l}\text { LE } \\
\text { curso de inglês instrumental/leitura } \\
\text { on line - uso de metáfora } \\
\text { para motivar professor e alunos }\end{array}$ \\
\hline $\mathrm{E} 47$ & $\begin{array}{l}\text { Opapel do professor e da } \\
\text { tecnologia educacional em uma } \\
\text { sociedade digital }(2001, \text { p. } 40)\end{array}$ & $\begin{array}{l}\text { LE } \\
\text { formação de professores } e \\
\text { e tecnologia educacional }\end{array}$ \\
\hline
\end{tabular}




\begin{tabular}{|c|c|c|}
\hline \begin{tabular}{|l} 
E49 \\
\end{tabular} & $\begin{array}{l}\text { Projeto de criação de revista } \\
\text { eletrônica em curso de inglês } \\
\text { instrumental (2001, p. 56) }\end{array}$ & $\begin{array}{l}\text { LM } \\
\text { capacitação docente em cursos } \\
\text { universitários/programa de } \\
\text { educação continuada e a distância } \\
\text { (UCPel = Univ.Católica Pelotas) }\end{array}$ \\
\hline E52 & $\begin{array}{l}\text { Estratégias pedagógicas em } \\
\text { situação de ensino semi-presencial } \\
\text { (2001, p. 58) }\end{array}$ & $\begin{array}{l}\text { LE } \\
\text { Inglês/leitura }\end{array}$ \\
\hline E55 & $\begin{array}{l}\text { Reações e atitudes de alunos de um } \\
\text { curso de leitura instrumental na } \\
\text { Internet (2001, p. 68) }\end{array}$ & $\begin{array}{l}\text { LE } \\
\text { leitura (ações e reações dos alunos - } \\
\text { comportamento do aprendiz em } \\
\text { contexto virtual) }\end{array}$ \\
\hline E56 & $\begin{array}{l}\text { WEBMAC (WEB MOTIVATIONAL } \\
\text { ANALYSIS CHECKLIST) e as } \\
\text { qualidades motivacionais de um } \\
\text { curso on-line de inglês de leitura } \\
\text { instrumental }(2001, \text { p. } 68)\end{array}$ & $\begin{array}{l}\text { LE } \\
\text { Leitura }\end{array}$ \\
\hline E57 & $\begin{array}{l}\text { Interação e interatividade em duas } \\
\text { modalidades de ensino de leitura } \\
\text { na Internet (2001, p. 69) }\end{array}$ & $\begin{array}{l}\text { LE } \\
\text { Leitura }\end{array}$ \\
\hline E61 & $\begin{array}{l}\text { Ensino mediado por computador } \\
\text { e a autonomia do aprendiz } \\
(2001, \text { p. } 108)\end{array}$ & $\begin{array}{l}\text { LE } \\
\text { leitura; autonomia do aprendiz }\end{array}$ \\
\hline \begin{tabular}{|l|} 
E64 \\
\end{tabular} & $\begin{array}{l}\text { Internet e ensino de inglês } \\
(2001, \text { p. 109) }\end{array}$ & $\begin{array}{l}\text { LE } \\
\text { laboratório de línguas estrangeiras - } \\
\text { inglês }\end{array}$ \\
\hline E66 & $\begin{array}{l}\text { Redigir: uma experiência de ensino } \\
\text { à distância }(2001, \text { p. } 129)\end{array}$ & $\begin{array}{l}\text { LM ou LE } \\
\text { leitura e produção de textos - ensino } \\
\text { presencial x ensino a distância }\end{array}$ \\
\hline E70 & $\begin{array}{l}\text { A autonomia do aluno: o ensino de } \\
\text { lingua inglesa via Internet } \\
\text { (2001, p. 157) }\end{array}$ & $\begin{array}{l}\text { LE } \\
\text { inglês via Internet - estratégias de } \\
\text { aprendizagem }\end{array}$ \\
\hline \begin{tabular}{|l|} 
E74 \\
\end{tabular} & $\begin{array}{l}\text { O uso do feedback nas atividades } \\
\text { de aprendizagem mediadas por } \\
\text { computador }(2001, \text { p. 208) }\end{array}$ & $\begin{array}{l}\text { LE } \\
\text { inglês - feedback e compreensão de } \\
\text { leitura }\end{array}$ \\
\hline E75 & $\begin{array}{l}\text { Estratégias de aprendizagem eo } \\
\text { ensino de língua inglesa via } \\
\text { Internet }(2001, \text { p. } 216)\end{array}$ & $\begin{array}{l}\text { LE } \\
\text { inglês via internet - estratégias de } \\
\text { aprendizagem }\end{array}$ \\
\hline \begin{tabular}{|l|} 
E77 \\
\end{tabular} & $\begin{array}{l}\text { The Internet in the area of } \\
\text { business administration studies } \\
\text { (2001, p. 222) }\end{array}$ & $\begin{array}{l}\text { LE } \\
\text { compreensão de textos por } \\
\text { universitários - área de administração }\end{array}$ \\
\hline
\end{tabular}




\begin{tabular}{|c|c|c|}
\hline \multicolumn{3}{|c|}{$\begin{array}{l}\text { GRUPO TEMÄTICO 2(a): Chats (Salas de Bate-Papo na Internet, Textos } \\
\text { de Conversação on-line) (17 trabalhos }=22 \%)\end{array}$} \\
\hline CÓDIGO & & TÍTULO ÁREA - LM, LE/ conteúdo \\
\hline$\overline{\mathrm{A} 1}$ & $\begin{array}{l}\text { A lingua italiana nos chats } \\
(2000, \text { p. 12) }\end{array}$ & $\begin{array}{l}\text { LE } \\
\text { ensino de italiano }\end{array}$ \\
\hline A3 & $\begin{array}{l}\text { Lingua portuguesa na Internet: } \\
\text { o caso das abreviaçôes em salas } \\
\text { de bate-papo }(2000, \text { p. } 49)\end{array}$ & $\begin{array}{l}\text { LM } \\
\text { Abreviações }\end{array}$ \\
\hline B7 & $\begin{array}{l}\text { Interação e construção de sentidos } \\
\text { em salas de bate-papo }(2000, \text { p. } 73)\end{array}$ & $\begin{array}{l}\text { LM } \\
\text { análise da conversação/org. das conversas }\end{array}$ \\
\hline C17 & $\begin{array}{l}\text { Interação on-line-análise de } \\
\text { interações em salas de chat } \\
(2001, \text { p. } 155)\end{array}$ & $\begin{array}{l}\text { LM } \\
\text { análise da conversação/conv.entre } \\
\text { amigos }\end{array}$ \\
\hline $\mathrm{C} 20$ & $\begin{array}{l}\text { Chat - diálogo oral ou escrito? } \\
(2001, \text { p. 208) }\end{array}$ & $\begin{array}{l}\text { LM } \\
\text { análise de constr. mistas fala e (e)scrit }\end{array}$ \\
\hline $\mathrm{C} 22$ & $\begin{array}{l}\text { A re-oralizacao-fala e escrita } \\
\text { em confluência na conversação } \\
\text { na Internet }(2001, \text { p. } 217)\end{array}$ & $\begin{array}{l}\text { LM } \\
\text { fala e escrita }\end{array}$ \\
\hline D31 & $\begin{array}{l}\text { Salas de bate-papo- uma análise } \\
\text { da produção discursiva de } \\
\text { adolescentes (2001, p. 38) }\end{array}$ & $\begin{array}{l}\text { LM } \\
\text { análise do discurso/ no projeto } \\
\text { "A construção, produção da escrita na } \\
\text { Internet e na escola: uma abordagem } \\
\text { sócio-cultural" }\end{array}$ \\
\hline D32 & $\begin{array}{l}\text { A produção discursiva nas salas } \\
\text { de bate-papo-formase } \\
\text { características }(2001, \text { p. } 43)\end{array}$ & $\begin{array}{l}\text { LM } \\
\text { análise de artefatos colhidos em salas } \\
\text { de bate-papo }\end{array}$ \\
\hline D33 & $\begin{array}{l}\text { A sala de bate-papo HIV-discurso, } \\
\text { identidade e sociedade (2001, p. 61) }\end{array}$ & $\begin{array}{l}\text { LM } \\
\text { como os sujeitos referenciam-se } \\
\text { identitariamente ao falarem de si } \\
\text { mesmos no espaço cibernético } \\
\end{array}$ \\
\hline D34 & $\begin{array}{l}\text { Identidades musicais juvenis nos } \\
\text { chats de música da Internet-um } \\
\text { ensaio de análise (2001, p. } 70)\end{array}$ & $\begin{array}{l}\text { LM } \\
\text { questões identitárias na Internet }\end{array}$ \\
\hline D35 & $\begin{array}{l}\text { A construção da identidade nas } \\
\text { salas de chat da Internet }- \text { uma } \\
\text { perspectiva feminista }(2001, \text { p. } 72)\end{array}$ & $\begin{array}{l}\text { LM } \\
\text { análise de } 250 \text { apelidos ou "nick names" } \\
\text { adotados por homens e mulheres, } \\
\text { reveladores de identidades masculina e } \\
\text { feminina como a reprodução de mitos } \\
\text { e estereótipos sexuais }\end{array}$ \\
\hline D36 & $\begin{array}{l}\text { O discurso de adolescentes na } \\
\text { Internet e a construçâo da } \\
\text { identidade (2001, p. 119) }\end{array}$ & $\begin{array}{l}\text { LM } \\
\text { discurso escrito produzido em interações } \\
\text { realizadas por adolescentes em canais de } \\
\text { chats (WEB e MIRC) e em e-mails e listas } \\
\text { de discussão }\end{array}$ \\
\hline
\end{tabular}




\begin{tabular}{|l|l|l|}
\hline D37 & $\begin{array}{l}\text { Alguém quer tc? Compreendendo } \\
\text { os enunciados de abordagem em } \\
\text { salas de bate-papo (2001, p. 132) }\end{array}$ & $\begin{array}{l}\text { LM } \\
\text { caracterizando recursos enunciativos } \\
\text { presentes nos diálogos dos chats }\end{array}$ \\
\hline D38 & $\begin{array}{l}\text { Construção discursiva de códigos } \\
\text { da escrita em sala de bate-papo- } \\
\text { uma trajetória inversa da apro- } \\
\text { priação do código escrito na } \\
\text { escrita inicial escolar (2001, p.148) }\end{array}$ & $\begin{array}{l}\text { LM } \\
\text { caracterização da conversação escrita na } \\
\text { Internet como um novo gênero escrito }\end{array}$ \\
\hline D39 & $\begin{array}{l}\text { Onickname como forma de } \\
\text { comunicação e processo de } \\
\text { construção da identidade de } \\
\text { usuários de salas de bate-papo } \\
\text { (2001, p. 151) }\end{array}$ & $\begin{array}{l}\text { LM } \\
\text { nickname como estratégia de } \\
\text { comunicação e construção da } \\
\text { identidade de seu usuário }\end{array}$ \\
\hline E67 & $\begin{array}{l}\text { A entrevista mediada por } \\
\text { computador: uma proposta de } \\
\text { análise da configuração do } \\
\text { gênero (2001, p. 141) }\end{array}$ & $\begin{array}{l}\text { LE ou LM } \\
\text { fala x escrita }\end{array}$ \\
\hline E68 & $\begin{array}{l}\text { Chat- língua escrita e língua } \\
\text { falada (2001, p. 150) }\end{array}$ & $\begin{array}{l}\text { LE ou LM } \\
\text { delimitação entre oralidade e escrita }\end{array}$ \\
\hline
\end{tabular}

GRUPO TEMÁTICO 2(b): Lista de Discussão (Fórum Eletrônico na Internet) - 3 trabalhos $=4 \%$

\begin{tabular}{|l|l|l|}
\hline CÓDIGO & TÍTULO & ÁREA - LM, LE/ conteúdo \\
\hline B11 & $\begin{array}{l}\text { Fórum na Internet - um gênero } \\
\text { bipertextual de discurso } \\
\text { (2000, p. 253) }\end{array}$ & $\begin{array}{l}\text { LM } \\
\text { gênero hipertextual }\end{array}$ \\
\hline C23 & $\begin{array}{l}\text { Pontuação e subjetividade em } \\
\text { textos de um fórum via Internet } \\
\text { (2001, p. 222) }\end{array}$ & $\begin{array}{l}\text { LM } \\
\text { atividade do sujeito na organização } \\
\text { rítmica em 100 textos coletados no } \\
\text { Fórum "Aborto" na Internet }\end{array}$ \\
\hline E62 & $\begin{array}{l}\text { Estágio supervisionado colaborativo: } \\
\text { uma proposta de educação à } \\
\text { distância na formação contínua do } \\
\text { professor de inglês (2001, p. 109) }\end{array}$ & $\begin{array}{l}\text { LE } \\
\text { ensino fundamental e médio }\end{array}$ \\
\hline
\end{tabular}

\section{GRUPO TEMÁTICO 3(a): Texto Eletrônico (9 trabalhos $=12 \%$ )}

\begin{tabular}{|l|l|l|}
\hline CÓDIGO & TÍTULO & ÁREA - LM, LE / conteúdo \\
\hline B6 & $\begin{array}{l}\text { Os caminhos da filologia - do texto } \\
\text { ao bipertexto (2000, p. 73) }\end{array}$ & $\begin{array}{l}\text { Filologia reflexão sobre } \\
\text { novo modo de linguagem }\end{array}$ \\
\hline C15 & $\begin{array}{l}\text { Os caminhos da filologia - do texto } \\
\text { ao bipertexto (2001, p. 112) }\end{array}$ & IDEM B6 \\
\hline B8 & $\begin{array}{l}\text { O sentido e seus suportes - } \\
\text { interpretando o texto eletrônico } \\
\text { (2000, p. 133) }\end{array}$ & $\begin{array}{l}\text { LM } \\
\text { novo suporte eletrônico e as novas } \\
\text { maneiras de ler }\end{array}$ \\
\hline
\end{tabular}




\begin{tabular}{|l|l|l|}
\hline C21 & $\begin{array}{l}\text { Um fino e frágil fio de Ariadne- } \\
\text { a interpretação do texto eletrônico } \\
\text { (2001, p. 213) }\end{array}$ & $\begin{array}{l}\text { LM } \\
\text { Novas estratégias de leitura intradiscurso/ } \\
\text { hipertexto e interdiscurso/links }\end{array}$ \\
\hline C29 & $\begin{array}{l}\text { Obipertexto e o texto eletrônico: } \\
\text { caracteristicas e desafios } \text { (p. 369) } \\
\text { Processos de referenciação no } \\
\text { texto eletrônico (2001, p. 381) }\end{array}$ & LM e LE \\
\hline E58 & $\begin{array}{l}\text { Uma análise lingüística tipo/ } \\
\text { exemplar de palavras } \\
\text { relacionadas com a metáfora } \\
\text { computacional em um corpus de } \\
\text { bipertextos } \text { (2001, p. 74) }\end{array}$ & $\begin{array}{l}\text { LM ou LE } \\
\text { terminologia computacional }\end{array}$ \\
\hline E71 & $\begin{array}{l}\text { A referência na Internet: artigos } \\
\text { acadêmicos eletrônicos } \\
\text { (2001, p. 159) }\end{array}$ & $\begin{array}{l}\text { LM ou LE } \\
\text { gêneros acadêmicos eletrônicos x } \\
\text { impressos }\end{array}$ \\
\hline E72 & $\begin{array}{l}\text { Ouso de textos eletrônicos na } \\
\text { aquisição de lingua estrangeira } \\
\text { (2001, p. 175) }\end{array}$ & $\begin{array}{l}\text { LE } \\
\text { aquisição de LE/TE literário e } \\
\text { "concordance" do Word Smith }\end{array}$ \\
\hline
\end{tabular}

\begin{tabular}{|l|l|l|}
\hline $\begin{array}{l}\text { GRUPO TEMÁTICO 3(b) - Correspondência eletrônica, e-mails (4 trabalhos } \\
\text { = 5\%) }\end{array}$ \\
\hline CÓDIGO & TÍTULO & ÁREA - LM, LE/conteúdo \\
\hline A5 & $\begin{array}{l}\text { O (des)uso dos conectivos nos } \\
\text { correios eletrônicos (sem resumo) }\end{array}$ & $\begin{array}{l}\text { LM } \\
\text { "(Des)uso dos conectivos nos correios } \\
\text { eletrônicos" }\end{array}$ \\
\hline C18 & $\begin{array}{l}\text { Os dêiticos na correspondência } \\
\text { eletrônica } \text { (p. 165). }\end{array}$ & $\begin{array}{l}\text { LM } \\
\text { papel dos dêiticos na organização } \\
\text { discursiva do gênero e-mail }\end{array}$ \\
\hline E48 & $\begin{array}{l}\text { A dêixis na organização discursiva } \\
\text { da correspondência eletrônica } \\
\text { (2001, p. 47) }\end{array}$ & $\begin{array}{l}\text { LM } \\
\text { dêixis/referência dêitica na } \\
\text { correspondência eletrônica expressões } \\
\text { dêiticas pessoais, espaciais, temporais } \\
\text { e discursivas na organização textual }\end{array}$ \\
\hline E63 & $\begin{array}{l}\text { Apragmática do mal-entendido } \\
\text { na interação via e-mail } \\
\text { (2001, p. 109) }\end{array}$ & $\begin{array}{l}\text { LM ou LE } \\
\text { princípio da cooperação }\end{array}$ \\
\hline
\end{tabular}




\begin{tabular}{|c|c|c|}
\hline \multicolumn{3}{|c|}{$\begin{array}{l}\text { GRUPO TEMÁTICO 4: Análise/Produção de Material Didático e/ou } \\
\text { Software( } 9 \text { trabalhos }=12 \%)\end{array}$} \\
\hline CÓDIGO & TÍTUlO & ÁREA - LM, LE/ conteúdo \\
\hline B10 & $\begin{array}{l}\text { A concepção de texto nos software } \\
\text { para o ensino de lingua portuguesa } \\
(2000, \text { p. 249-250) }\end{array}$ & $\begin{array}{l}\text { LM } \\
\text { conceito de texto, ensino de produção } \\
\text { textual }\end{array}$ \\
\hline $\mathrm{C} 24$ & $\begin{array}{l}\text { Implementação de situações } \\
\text { comunicativas em ambientes virtuais } \\
\text { em uma ferramenta computacional } \\
\text { para ensino de inglês como lingua } \\
\text { estrangeira (2001, p. 268) }\end{array}$ & $\begin{array}{l}\text { LE } \\
\text { ensino de inglês }\end{array}$ \\
\hline $\mathrm{C} 25$ & $\begin{array}{l}\text { O tratamento do erro em software } \\
\text { destinado ao ensino de lingua } \\
\text { inglesa (2001, p. 322) }\end{array}$ & $\begin{array}{l}\text { LE } \\
\text { ensino de inglês }\end{array}$ \\
\hline $\mathrm{C} 27$ & $\begin{array}{l}\text { Uma proposta para a avaliação } \\
\text { de materiais em software para o } \\
\text { ensino de línguas estrangeiras } \\
(2001, \text { p. } 339)\end{array}$ & $\begin{array}{l}\text { LE } \\
\text { ensino de inglês) -Projeto AVAL/UFC }\end{array}$ \\
\hline $\mathrm{C} 28$ & $\begin{array}{l}\text { A tecnologia instrucional no ensino } \\
\text { de pronúncia em lingua estrangeira } \\
\text { (p. } 365 \text { ) }\end{array}$ & $\begin{array}{l}\text { LE } \\
\text { ensino de LE } \\
\text { mediado pelo computador }\end{array}$ \\
\hline $\mathrm{E} 51$ & $\begin{array}{l}\text { Estratégias de ensino e aprendizagem } \\
\text { adotadas na elaboração e uso de } \\
\text { materiais construídos para estudo } \\
\text { auto-monitorado (2001, p. 58) }\end{array}$ & LE leitura em inglês \\
\hline E54 & $\begin{array}{l}\text { Preparação e concretização de um } \\
\text { curso online de leitura instrumental } \\
(2001, \text { p. } 68)\end{array}$ & $\begin{array}{l}\text { LE } \\
\text { leitura em inglês }\end{array}$ \\
\hline E65 & $\begin{array}{l}\text { Dicas sobre o uso do Wordsmith } \\
\text { "Tools" (2001, p. 113) }\end{array}$ & $\begin{array}{l}\text { LM ou LE } \\
\text { - interação em grupo de discussão via } \\
\text { e-mail }\end{array}$ \\
\hline E76 & $\begin{array}{l}\text { A interdisciplinariedade na } \\
\text { elaboração de um curso de inglês } \\
\text { instrumental via WEB: estudo de } \\
\text { caso }(2001, \text { p. } 220)\end{array}$ & $\begin{array}{l}\text { LE } \\
\text { interdisciplinaridade na elaboração de } \\
\text { curso de inglês instrumental - inglês e } \\
\text { ciências da computação }\end{array}$ \\
\hline
\end{tabular}

\begin{tabular}{|l|l|l|}
\hline \multicolumn{3}{|l|}{ GRUPO TEMÁTICO 5: Estudos Lingüisticos e Novas Tecnologias (8 trabalhos = 10\%) } \\
\hline CÓDIGO & TÍTULO & ÁREA - LM, LE/conteúdo \\
\hline B9 & $\begin{array}{l}\text { A influência das tecnologias de } \\
\text { comunicação no léxico lingua } \\
\text { portuguesa }(2000, \text { p. 216) }\end{array}$ & $\begin{array}{l}\text { LM } \\
\text { reflexão sobre novas tecnologias e } \\
\text { influências no léxico de LP }\end{array}$ \\
\hline C12 & $\begin{array}{l}\text { Lingüistica, novas tecnologiase } \\
\text { teorias da ação }(\text { sem resumo - } \\
\text { programação, 2000, p. 11) }\end{array}$ & $\begin{array}{l}\text { LM } \\
\text { "Novas tecnologias comunicacionais e } \\
\text { educação continuada" (trabalho teórico) }\end{array}$ \\
\hline
\end{tabular}




\begin{tabular}{|l|l|l|}
\hline D40 & $\begin{array}{l}\text { Representação e identidade no } \\
\text { caso Moara na Internet } \\
(2001, \text { p. 155) }\end{array}$ & $\begin{array}{l}\text { LM } \\
\text { discursos instituidores de dicotomias: } \\
\text { norte/sul, científico/religioso etc. }\end{array}$ \\
\hline E42 & $\begin{array}{l}\text { Applied linguistics in the age of } \\
\text { bypertechnology (2001, p. 31) }\end{array}$ & $\begin{array}{l}\text { LM e LE } \\
\text { LA e Hypertecnologia }\end{array}$ \\
\hline E53 & $\begin{array}{l}\text { Questôes de pedagogia crítica na } \\
\text { rede: leitura, escrita e constituição } \\
\text { do sujeito crítico (2001, p. 59) }\end{array}$ & $\begin{array}{l}\text { LM ou LE } \\
\text { leitura e escrita - atitudes pedagógicas na } \\
\text { era digital }\end{array}$ \\
\hline E60 & $\begin{array}{l}\text { Mundos virtuais: imersão e criação } \\
\text { de espaços perceptivos (2001, p. 89) }\end{array}$ & $\begin{array}{l}\text { LM ou LE } \\
\text { análise do discurso }\end{array}$ \\
\hline E69 & $\begin{array}{l}\text { Um estudo de gênero de artigos } \\
\text { acadêmicos em periódicos } \\
\text { eletrônicos brasileiros (2001, p.153) }\end{array}$ & $\begin{array}{l}\text { LE ou LM } \\
\text { interação autor-texto-leitor } \\
\text { LM ou LE }\end{array}$ \\
\hline E73 & $\begin{array}{l}\text { A configuração do gênero anúncio } \\
\text { pessoal no meio eletrônico } \\
\text { (2001, p. 177) }\end{array}$ & \\
\hline
\end{tabular}

\begin{tabular}{|c|c|c|}
\hline \multicolumn{3}{|c|}{$\begin{array}{l}\text { GRUPO TEMÁTICO 6: Revista, dicionário ou Thesaurus eletrônicos } \\
\text { (3 trabalhos }=4 \% \text { ) }\end{array}$} \\
\hline CÓDIGO & TÍTULO & ÁREA - LM, LE/ conteúdo \\
\hline C26 & $\begin{array}{l}\text { O "TEP": construção de um } \\
\text { thesaurus eletrônico para o } \\
\text { português do Brasil } \text { (p. } 337 \text { ) }\end{array}$ & $\begin{array}{l}\mathrm{LM} \\
\text { thesaurus eletrônico p/ português do } \\
\text { Brasil) }\end{array}$ \\
\hline $\mathrm{E} 45$ & $\begin{array}{l}\text { Comunidades de aprendizagem } \\
\text { on-line e o ensino de línguas } \\
(2001, \text { p. } 39)\end{array}$ & $\begin{array}{l}\text { LE } \\
\text { leitura - elaboração dicionário } \\
\text { eletrônico) }\end{array}$ \\
\hline E50 & $\begin{array}{l}\text { Comunidade online para } \\
\text { aprendizagem cooperativa: } \\
\text { desenvolvendo novas } \\
\text { competências }(2001, \text { p. } 55)\end{array}$ & $\begin{array}{l}\text { LE } \\
\text { Inglês }\end{array}$ \\
\hline
\end{tabular}

\begin{tabular}{|c|c|c|}
\hline \multicolumn{3}{|c|}{$\begin{array}{l}\text { GRUPO TEMÁTICO 7: Hipertexto, homepage, linguagem eletrônica } \\
(2 \text { trabalhos }=3 \%)\end{array}$} \\
\hline CÓDIGO & TÍTULO & ÁREA - LM, LE/ conteúdo \\
\hline A2 & $\begin{array}{l}\text { Disponibilização de informações } \\
\text { na Internet (2000, p. 36) }\end{array}$ & $\begin{array}{l}\text { Linguagem técnica } \\
\text { (informações na WEB) }\end{array}$ \\
\hline E44 & $\begin{array}{l}\text { INGREDE e a linguagem de } \\
\text { programação JAVA (2001, p. 34) }\end{array}$ & $\begin{array}{l}\text { LE e LM } \\
\text { linguagem de programação JAVA }\end{array}$ \\
\hline
\end{tabular}

O quadro seguinte sintetiza a distribuição dos títulos/resumos analisados: 
QUADRO 3 - Distribuição por Tema, Foco, Área/Língua-alvo

\begin{tabular}{|l|r|r|r|r|r|r|r|}
\hline Tema dos trabalhos/Objeto estudado & $\mathrm{N}$ & Foco & & & Área & & \\
\hline & & Meio & Fim & Ambos & LM & LE & LM/LE \\
\hline $\begin{array}{l}\text { Ensino/aprendizagem de línguas } \\
\text { mediado pelo computador }\end{array}$ & 20 & 13 & 4 & 3 & 7 & 13 & - \\
\hline Chats (salas de bate-papo) & 17 & 7 & 7 & 3 & 14 & 1 & 2 \\
\hline Texto eletrônico & 9 & 2 & 1 & 6 & 5 & 2 & 2 \\
\hline E-mails/correspondência eletrônica & 4 & 4 & - & - & - & - & 4 \\
\hline $\begin{array}{l}\text { Análise/produção de material } \\
\text { instrucional e/ou software }\end{array}$ & 9 & 8 & - & 1 & 1 & 7 & 1 \\
\hline $\begin{array}{l}\text { Estudos lingüísticos e novas } \\
\text { tecnologias }\end{array}$ & 8 & 5 & 2 & 1 & 5 & - & 3 \\
\hline $\begin{array}{l}\text { Periódicos, revistas, dicionários, } \\
\text { ou thesaurus eletrônicos }\end{array}$ & 3 & 3 & - & - & 1 & 2 & - \\
\hline $\begin{array}{l}\text { Fórum eletrônico na Internet } \\
\text { (listas de discussão) }\end{array}$ & 3 & 2 & 1 & - & 2 & 1 & - \\
\hline $\begin{array}{l}\text { Hipertexto, homepage e } \\
\text { linguagem eletrônica }\end{array}$ & 3 & - & 2 & 1 & - & - & 3 \\
\hline \multicolumn{1}{|c|}{ N } & 76 & 44 & 17 & 15 & 35 & 23 & 18 \\
\hline
\end{tabular}

A mesma distribuição apresentada no Quadro 3 pode ser visualizada no gráfico a seguir, sendo detalhada na próxima seção.

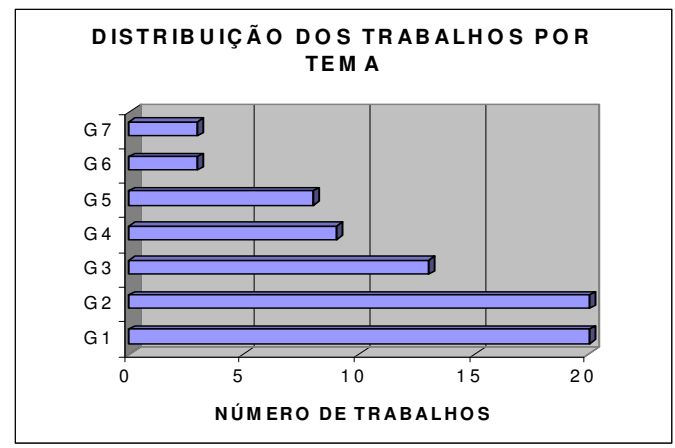

Gráfico 3 - Distribuição dos trabalhos por tema

LEGENDA: G1=Ensino-aprendizagem de línguas mediado pelo computador; G2=chats/ fórum de discussão na Internet; G3=texto eletrônico/e-mails; G4=análise/produção de material instrucional e/ou software; G5=estudos lingüísticos/novas tecnologias; G6=periódicos/revistas/dicionários/thesaurus eletrônicos; G7=hipertexto/ homepage/ linguagem eletrônica. 


\section{Assuntos/problemas investigados nos estudos}

Vejamos em maior detalhe os resultados encontrados, aqui organizados por GRUPOS TEMÁTICOS e numerados em ordem decrescente - do mais para o menos representativo na amostra:

Grupo 1: O objeto de estudo priorizado na amostra foi ensino-aprendizagem de linguas mediado pelo computador (26,3\%). Nesse conjunto, a maioria dos trabalhos focaliza a tecnologia digital como meio e eles são sobre LE/inglês (65\%). Apenas 35\% dos trabalhos tratam de LM.

- Os estudos em LE (13), de um lado, abordam leitura em inglês instrumental (8, representando 61\% desses estudos), explorando: motivação, feedback e estratégias de leitura (4), comportamento e autonomia do aluno em ambiente virtual (2), interação (1), relato de experiência mista $(75 \%$ em meios virtuais - chats, emails, fóruns e 25\% presencial) (1). De outro lado, há estudos em LE descrevendo tipologia de ambientes virtuais de ensino da linguagem (1), discutindo formação de professores e tecnologia digital (1), explorando interação (1) e estratégias de aprendizagem em meio virtual (2).

- Já os estudos em LM (7) caracterizam o ensino não-presencial pela Internet/interação no ciberespaço, versando sobre: curso de pósgraduação em filologia /a língua na literatura (1); ensino de LP pela Internet - princípios teóricos-metodológicos, interação professor-aluno/formas de diálogo/sociolongüística interacional, fala/escrita - abertura de tópico discursivo (3); curso de redação para vestibulandos, comparação entre ensino de redação presencial/a distância (2); capacitação docente (1).

Grupo 2: ${ }^{3}$ A seguir, destacam-se os trabalhos sobre chats (salas de bate-papo - 22,36\% ) que, reunidos a outros 3,94\% sobre fórum eletrônico na Internet (listas de discussão), figuram como uma segunda área

\footnotetext{
${ }^{3}$ Os dados dos Grupos Temáticos 2 e 3 constituiram um minicorpus, analisado em outro estudo - VIEIRA, Iúta Lerche. "Tendências de pesquisa em gêneros virtuais: focalizando a relação oral/escrito". III Congresso Internacional da Associação Brasileira de Lingüistica/ABRALIN, Rio de Janeiro, 13 a 15/03/2003, Sessão Coordenada "Oralidade/Escrita em Gêneros Virtuais e Midiáticos". O trabalho descreve como a pesquisa lingüística no Brasil focaliza a problemática oralidade/ escrita, com a introdução da tecnologia eletrônica para ler/escrever, no período 2000/2001, identificando o que está sendo investigado sobre a relação e as interfaces fala/escrita em trabalhos envolvendo salas de bate-papo/listas de discussão e texto eletrônico/ e-mails.
} 
importante nesses estudos. Chats e fórum eletrônico juntos têm o mesmo percentual do primeiro grupo (26,3\%). Desses trabalhos, $74 \%$ são em LM e apenas um em LE, sobre ensino de italiano. Há outros 4 trabalhos que não especificam a língua-alvo.

- Dos 17 trabalhos sobre chats identificados na amostra, metade focaliza esse tipo de comunicação virtual como meio para estudar questões convencionais e a outra metade busca aspectos inovadores, examinando os chats como fim. Aqui é importante chamar a atenção para o fato de que essa temática é a que reúne maior número de estudos explorando o meio virtual como um fim. Em outras palavras, os chats se constituem, de fato, numa forma de linguagem nova com marcas do oral e do escrito, e têm recebido muita atenção dos pesquisadores no campo da linguagem. (Não esquecendo que alguns trabalhos da amostra foram incluídos no grupo de ensino/ aprendizagem mediado pelo computador, por tratarem de assuntos do ensino, como, por exemplo, aulas-chats/aulas-conferências.)

- Em nossa amostra, os estudos abordando chats como meio dão prioridade à análise do discurso e focalizam:

- escrita "teclada" como prática social e/ou discurso do adolescente (2);

- sala de bate-papo HIV/UOL (1);

- música na Internet (1);

- construção de identidade/perspectiva feminista (1).

- Outros 3 estudos investigando chats como meio focalizam: léxico/ repertório (1); morfologia (1); pontuação e ritmo (1).

- Os estudos abordando chats como fim se voltam quase que exclusivamente para gênero, caracterizando-os como "gêneros textuais emergentes" (apenas um deles foge a esse padrão, tratando de aquisição de códigos de escrita em ordem inversa à aquisição infantil, no sentido de "desconstruir" a escrita). Nesse grupo majoritário figuram estudos sobre: interação on line (1); chats como novo gênero discursivo (2); marcas de "re-oralização" (1); modos de iniciar conversas virtuais (1); chats com entrevistas (1).

Grupo 3: A terceira área de estudo mais freqüente na amostra foi texto eletrônico (12\%) e emails/correspondência eletrônica $(5,2 \%)$, perfazendo 17,10\%. Neles, o foco de análise predominante ou é o meio, ou ambos $($ meio + fim $)$, significando que a nova tecnologia "pode transformar um gênero e projetar novas estratégias de textualização" (DIAS, 2001). Quanto à língua-alvo, quando mencionada, há um leve predomínio da língua materna. Esse trabalhos caracterizam o texto eletrônico, face ao texto tipográfico, explorando: 
- livro digital X livro impresso (3);

- leitura do texto eletrônico em jornal on line (2),

- leitura do hipertexto (1);

- terminologia computacional (1);

- gêneros acadêmicos eletrônicos x impressos (1);

- aquisição de LE/texto eletrônico literário /"Concordance"/ WordSmith.

- Todos os estudos sobre e-mails e correspondência elerônica são em LM e tratam de mecanismos coesivos: (des)uso dos conectivos (1); papel dos dêiticos na organização discursiva do gênero e-mail (1) e dêxis/referência (1).

Grupo 4: $\quad$ Em quarto lugar figura análise/produção de material instrucional e/ ou software, com 11,84\% de produtividade nos estudos em geral. Dentro desse grupo, a maioria absoluta dos trabalhos (89\%) tem o computador como meio e o inglês como língua-alvo (78\%). Os assuntos focalizados são:

- concepção de texto em softwares para o ensino de LP/produção textual (1);

- elaboração de software para o ensino de inglês para guias turísticos pela Internet (1);

- tratamento de erros em materiais para o ensino de línguas pelo computador (1);

- avaliação de materiais didáticos em formato multimídia disponíveis no mercado (1);

- tecnologia instrucional no ensino da pronúncia (1);

- dificuldades na elaboração de material pedagógico em meios virtuais/leitura em inglês (1);

- processo de criação de curso on line de leitura em inglês (1);

- análise do software WordSmith para análise textual (1);

- interdisciplinaridade na elaboração de curso de inglês instrumental (1).

Grupo 5: $\quad$ Em quinto lugar, representando 10,52\% dos trabalhos, estudos lingüísticos e novas tecnologias. Aqui também o foco principal é a tecnologia digital como meio, mas a língua priorizada nos estudos é a língua materna. Os temas contemplados são:

- léxico/criação de novos vocábulos na Internet (1);

- lingüística e suas interfaces (2) - LA/Hipertecnologia; novas tecnologias comunicacionais e educação continuada; 
- análise de discurso (2) - política editorial da Revista Moara 2000; processos de formação de sentido na linguagem hipermidiática;

- leitura e escrita/atitudes pedagógicas na era digital (1);

- gênero (2 ) - artigo eletrônico; anúncio pessoal homossexual.

Grupo 6: Com uma representatividade bem menor, em sexta posição no levantamento, situam-se os trabalhos sobre periódicos, revistas, dicionários, thesaurus eletrônicos (3,94\%), tendo o computador mais como meio e priorizando LE. Esses trabalhos tratam de assuntos relativos a:

- léxico/representação da sinonímia e antonímia em thesaurus eletrônicos para o português do Brasil (1);

- leitura em LE/elaboração de dicionário eletrônico (1);

- criação de revista eletrônica em curso de inglês instrumental (1).

Grupo 7: Em último lugar figuram 2 trabalhos sobre bipertexto, bomepage e linguagem eletrônica (2,63\%) - elaboração de homepages/linguagem HTML; linguagem de programação JAVA e um único sobre mundos virtuais discutindo novas tecnologias em geral (1,31\%).

\section{Modo como a temática tecnologia e letramento digital é abordada nos estudos}

Um ponto importante nesta investigação era identificar o foco dos trabalhos científicos apresentados no período em questão. Tal como definida na seção "Tendências dos estudos sobre letramento digital 2000/2001", esta categoria de análise refere-se à relação entre conteúdo dos trabalhos (questões problemática), forma (suporte, contexto) e função (significado/interpretação dos resultados). Assim, procuramos identificar os trabalhos da amostra que abordassem dados eletrônicos ou letramento digital apenas como meio (questões conhecidas em um novo suporte) ou como fim (questões novas num suporte também novo, ou questões conhecidas com uma função nova decorrente do novo suporte). O gráfico revela o que foi encontrado: 


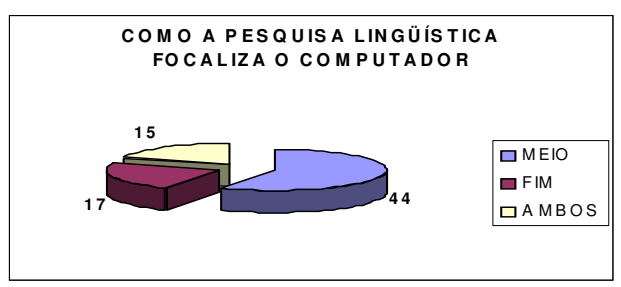

Gráfico 4 - Como a pesquisa lingüística focaliza o computador

\section{Línguas focalizadas nos estudos}

O foco prioritário nas pesquisas em termos de língua-alvo foi a língua materna (46\%), seguido pela língua estrangeira/inglês (30\%), havendo $24 \%$ onde a língua não é relevante. Observando a distribuição equilibrada das pesquisas quanto à língua, cabe observar uma tendência de deslocamento da importância da língua, ao se abordar o letramento digital, de caráter multilingüe (exceção feita aos estudos sobre ensino mediado pelo computador).

O gráfico a seguir apresenta a distribuição das pesquisas, por língua focalizada nos trabalhos:

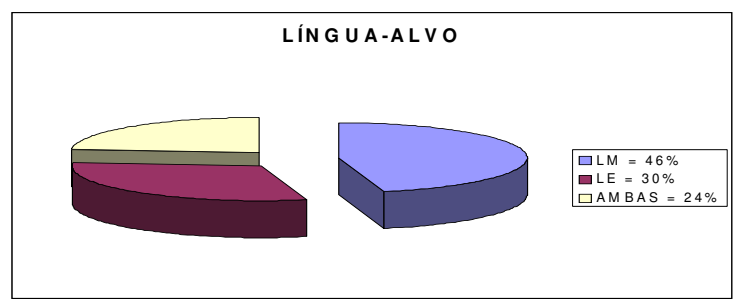

Gráfico 5 - Língua-Alvo

\section{Metodologias e modalidades de estudos conduzidos no período 2000/2001}

Quanto à metodologia dos trabalhos apresentados no período, o que foi possível levantar com segurança a partir de um corpus constituído por títulos/resumos foi a modalidade de estudos conduzidos na pesquisa sobre TE/LD. O quadro seguinte mostra, em termos metodológicos, quais os tipos de investigação priorizados: 
QUADRO 4 - Distribuição dos Trabalhos por Modalidades de Estudos

\begin{tabular}{|c|c|c|c|c|c|c|c|}
\hline Eventos & \multirow[t]{2}{*}{ A } & \multirow[t]{2}{*}{$\mathrm{B}$} & \multirow[t]{2}{*}{$\mathrm{C}$} & \multirow[t]{2}{*}{$\mathrm{D}$} & \multirow[t]{2}{*}{$\mathrm{E}$} & \multirow[t]{2}{*}{ Total } & \multirow[t]{2}{*}{$\%$} \\
\hline Modalidades / Metodologia & & & & & & & \\
\hline Estudo teórico (reflexão) & 1 & 2 & 8 & 1 & 15 & 27 & $37 \%$ \\
\hline Estudo descritivo & 1 & 1 & 4 & - & 8 & 14 & $19 \%$ \\
\hline Relato de experiência & - & - & 2 & - & 6 & 8 & $11 \%$ \\
\hline Estudo experimental & - & 2 & 1 & 2 & 3 & 8 & $11 \%$ \\
\hline Observação (participante) & - & - & 2 & 5 & 1 & 8 & $11 \%$ \\
\hline Estudo exploratório (piloto) & 2 & 1 & 1 & 1 & 1 & 6 & $8 \%$ \\
\hline Estudo de caso & - & - & - & - & 2 & 2 & $3 \%$ \\
\hline Total & 4 & 6 & 18 & 9 & 36 & 73 & $100 \%$ \\
\hline
\end{tabular}

* Obs: Há 2 estudos sem resumo (um no evento A e outro no evento C) e um estudo repetido $(\mathrm{B} 6=\mathrm{C} 15)$, perfazendo um total exato de 73 trabalhos, cuja metodologia é perceptível através da leitura dos resumos.

Como se pode visualizar no Quadro 4, a maioria dos estudos (37\%) apresenta reflexão teórica sobre essas novas questões. A seguir, vieram os estudos descritivos (19\%), descrevendo novos padrões de ensino/comunicação/usos da tecnologfia. Os estudos experimentais na área ainda são escassos (11\%). Relatos de experiência e de observações tiveram o mesmo percentual. Estudos exploratórios (8\%), seguidos de estudos de caso (3\%), completam a metodologia empregada na investigação lingüística em novos letramentos. Essa distribuição pode ser visualizada abaixo:

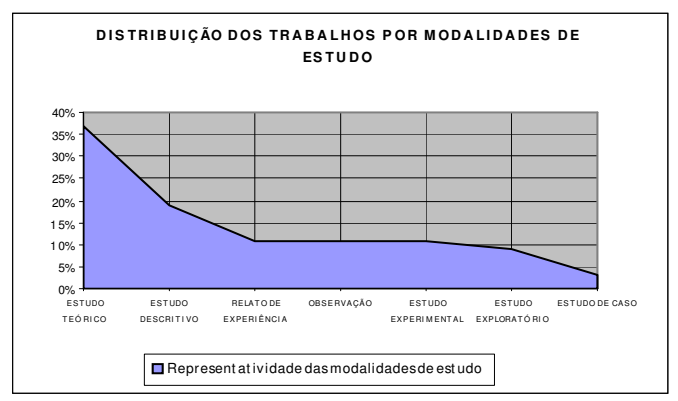

Gráfico 6 - Distribuição dos trabalhos por modalidades de estudo

A tendência a priorizar metodologia qualitativa, de base descritiva, a nosso ver, pode ter relação com dois aspectos: a novidade 
do tema na pesquisa lingüística e a velocidade com que esses novos letramentos são implementados, fazendo com que a atualização tecnológica seja priorizada em relação à pesquisa na área.

Discorrendo sobre as relações letramento/tecnologia, Leu (2000, p. 761) refere-se a esse fenômeno como "relação dêitica", aquela em que o letramento se define de forma flexível, remetendo ao contexto de uso a que se refere, onde o domínio das inovações tecnológicas chega a tomar o lugar daquilo a que a inovação se aplica, fazendo com que os meios se transformem em fins, dificultando uma tradição de pesquisa na área.

Essa questão já fora observada por nós na própria estruturação dos resumos científicos envolvendo a temática texto eletrônico/ letramento digital. Na amostra analisada há uma nítida tendência em atribuir maior relevo à introdução, face aos aspectos teóricometodológicos ou resultados de pesquisa neles apresentados. Verificamos que nas introduções desses resumos havia um grau de especificação muito maior na colocação do problema e justificativa da investigação do que nos demais aspectos. A metodologia muitas vezes era apenas mencionada ou sugerida. Ao mesmo tempo, havia pouca fundamentação teórica envolvendo as questões em que a tecnologia virtual seria abordada como fim de pesquisa. ${ }^{4}$

\section{Origem das investigações e forma de apresentação nos eventos}

As informações reunidas no quadro abaixo procuram responder às seguintes questões:

- Que estados e regiões são responsáveis pela pesquisa na área?

- Que tipo de instituições concentram a pesquisa na área?

- Qual a modalidade acadêmica de apresentação dos trabalhos?

- Como os autores trabalharam: individualmente ou em grupo?

\footnotetext{
${ }^{4}$ Esse problema gerou interessante trabalho de final de curso na UECE, elaborado em 2002 por Carmem Sílvia de Carvalho Rêgo, então bolsista de Iniciação Científica da FUNCAP, sob minha orientação. O estudo intitula-se "A introdução em resumos científicos: aspectos de organização retórica na temática letramento/ novas tecnologias" (14 p.).
} 
QUADRO 5 - Distribuição das Pesquisas por Estados, Instituições, Modalidades de Apresentação nos Eventos e Participação dos Autores

\begin{tabular}{|c|c|c|c|c|c|c|c|c|c|c|c|c|c|c|c|c|}
\hline \multirow{2}{*}{\multicolumn{2}{|c|}{ Estados }} & \multicolumn{4}{|c|}{ Instituições } & \multicolumn{7}{|c|}{ Modalidades } & \multirow{2}{*}{\multicolumn{3}{|c|}{$\begin{array}{c}\text { Participação } \\
\text { Ind. Grup. NId. }\end{array}$}} & \multirow[b]{2}{*}{$\mathbf{N}$} \\
\hline & & \multicolumn{4}{|c|}{ F $\quad$ E $\quad P$ NId } & CI & & MR & PL & & PT & NId & & & & \\
\hline Sudeste & $\mathrm{SP}$ & 1 & 9 & 7 & 3 & 03 & 14 & 2 & - & 1 & - & - & 15 & 5 & - & 20 \\
\hline Sudeste & $\mathrm{MG}$ & 17 & - & - & 1 & 6 & 9 & 1 & 2 & - & - & - & 17 & 1 & - & 18 \\
\hline Sul & RS & 9 & - & 4 & 2 & 7 & 4 & 3 & 1 & - & - & - & 9 & 6 & - & 15 \\
\hline \begin{tabular}{|l} 
Nordeste \\
\end{tabular} & $\mathrm{CE}$ & 5 & 4 & - & - & 1 & 7 & - & - & - & - & 1 & 7 & - & 2 & 9 \\
\hline Sudeste & RJ & 2 & 2 & 1 & - & - & 3 & 2 & - & - & - & - & 4 & 1 & - & 5 \\
\hline Nordeste & BA & - & 1 & - & 1 & 1 & - & 1 & - & - & - & - & 2 & - & - & 2 \\
\hline Nordeste & PE & 1 & - & - & - & - & - & 1 & - & - & - & - & 1 & - & - & 1 \\
\hline Nordeste & $\mathrm{RN}$ & 1 & - & - & - & - & - & 1 & - & - & - & - & 1 & - & - & 1 \\
\hline Nordeste & PB & 1 & - & - & - & - & 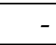 & - & - & - & 1 & - & 1 & - & - & 1 \\
\hline Nordeste & MA & 1 & - & - & - & 1 & - & - & - & - & - & - & 1 & - & - & 1 \\
\hline Nordeste & PA & 1 & - & - & - & 1 & . & - & - & - & - & - & 1 & - & - & 1 \\
\hline C. Oeste & MT & 1 & - & - & - & - & 1 & - & - & - & - & - & 1 & - & - & 1 \\
\hline Estrangei & & - & - & - & 1 & - & - & - & 1 & - & - & - & 1 & - & - & 1 \\
\hline $\mathbf{N}$ & & 40 & 16 & 12 & 8 & 20 & 38 & 11 & 4 & 1 & 1 & 1 & 61 & 13 & 2 & 76 \\
\hline
\end{tabular}

LEGENDA - Instituições: F (federais), E (estaduais), P (particulares), NId (não identificada); Modalidades: CI (comunicação individual), CC (comunicação coordenada), MR (mesa-redonda), PL (plenária), SP (simpósio), PT (poster), NId (não identificada); Participação: Ind (individual), Grup (grupal), NId (não identificada).

\section{Representatividade das regiões e estados brasileiros na pesquisa sobre TE/LD}

Os dados mostram que a temática vem sendo estudada em todas as regiões do país:

$\begin{array}{lcl}\text { Regiões } & \text { Trabalhos } & \mathbf{0} \\ \text { Sudeste } & 43 & 57 \\ \text { Nordeste } & 15 & 20 \\ \text { Sul } & 15 & 20 \\ \text { Centro-Oeste } & 01 & 2 \\ \text { Norte } & 01 & 1\end{array}$

A representatividade dos estados foi a seguinte ${ }^{5}$ :

\footnotetext{
${ }^{5}$ Registrou-se, ainda, um trabalho de instituição estrangeira e um municipal, cujo estado não foi identificado pelo resumo.
} 


$\begin{array}{lcc}\text { Estados } & \text { Trabalhos } & \text { \% } \\ \text { São Paulo } & 20 & 27 \\ \text { Minas Gerais } & 18 & 24 \\ \text { Rio Grande do Sul } & 15 & 20 \\ \text { Ceará } & 9 & 12 \\ \text { Rio de Janeiro } & 5 & 7 \\ \text { Bahia } & 2 & 4 \\ \text { Maranhão } & 1 & 1 \\ \text { Pernambuco } & 1 & 1 \\ \text { Rio Grande do Norte } & 1 & 1 \\ \text { Paraíba } & 1 & 1 \\ \text { Pará } & 1 & 1\end{array}$

\section{Instituições responsáveis pela pesquisa em TE/LD}

As instituições públicas lideram a pesquisa na área (74\%). Entre elas, as federais foram responsáveis por $53 \%$ dos trabalhos, seguidas pelas estaduais (21\%). As instituições particulares representam 16\% da produção acadêmica. 1\% dos trabalhos é de instituição estrangeira e 9\% dos trabalhos não apresentaram identificação suficiente para uma classificação segura.

\section{Forma de apresentação dos trabalhos em eventos científicos}

Quanto à modalidade acadêmica dos trabalhos, 50\% foram apresentados em Comunicações Coordenadas, 27\% em Comunicações Individuais, 15\% em Mesas-Redondas e 4\% em Plenárias, 1\% em Simpósio e 1\% em Pôster.

Essa distribuição merece um comentário. Embora nos congressos seja comum uma maior freqüência de trabalhos sob a forma de comunicações individuais/coordenadas, a pesquisa em TE/LD, iniciante no Brasil, ainda não tem um status acadêmico privilegiado. Sobre o fato de metade dos trabalhos ser apresentada em Sessões Coordenadas, também não se devem tirar conclusões precipitadas. Na verdade, a forma de comunicação coordenada não significa parceria nas investigações, nem dentro de uma mesma universidade. Quando muito reflete uma organização temática conveniente e de maior projeção nos congressos. Os aspectos considerados no tópico anterior sobre intercâmbio de idéias/projetos na área reforçam essa interpretação. 


\section{Autoria e colaboração nos trabalhos}

A grande maioria dos trabalhos foi individual (80\%). Os trabalhos em grupo identificados somaram apenas 7\%, ficando outros 3\% sem identificação, conforme mostra o gráfico seguinte:

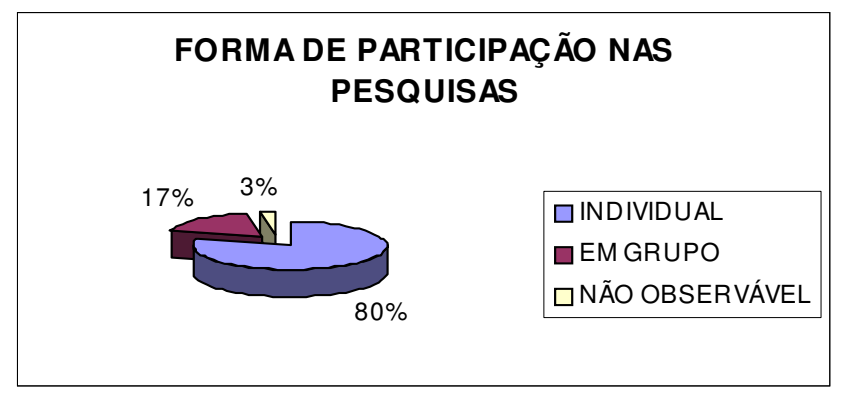

Gráfico 7 - Forma de participação nas pesquisas

A investigação em grupo aparece por ordem de maior freqüência nos Estados de São Paulo, Rio Grande do Sul, Minas Gerais e Rio de Janeiro.

Em um mesmo Estado, é comum a incidência de vários estudos que seguem uma mesma linha de investigação, sem que haja referências à cooperação entre pesquisas. Apenas nos Estados do Rio Grande do Sul, de Minas Gerais, do Mato Grosso e do Ceará é observável a participação de mais de uma instituição em um mesmo trabalho. Já a cooperação entre estados (Minas Gerais e Mato Grosso), só foi verificada em um dos trabalhos. Há, assim, muito pouca cooperação nas investigações. São raros os casos em que encontramos parceria entre pesquisadores, e mais raros ainda entre instituições.

\section{Comentários Finais}

Esse é o quadro da pesquisa em letramento/tecnologia no Brasil no âmbito dos estudos lingüísticos, de meados de 2000 a 2001. Em termos absolutos, a atividade investigativa na área ainda era pouco significativa ( $3 \%$ dos trabalhos apresentados em 5 eventos científicos), mas com nítidas tendências de crescimento e diversificação de estudos, refletindo a tendência exploratória verificada em nível internacional, com alguns anos de atraso. No período focalizado, os dados eletrônicos 
funcionaram mais como um suporte novo para investigar as mesmas questões, do que elementos para investigar, de forma substantiva, novas formas de letramento. O trabalho cooperativo entre lingüistas, raro em todos os níveis de atuação (institucional, regional ou nacional), pode ser uma promessa para a formação de uma tradição de pesquisa mais sedimentada na área.

\section{Referências Bibliográficas}

BASTOS, L.; LOPES, L. P. M. (Coord.). Simpósio Nacional Discurso, Identidade e Sociedade, 17 a 19 de maio de 2001- Caderno de Resumos. Rio de Janeiro: PUC- Rio, UFRJ, 2001. 170 p.

CRYSTAL, D. El Lenguage e Internet. Madri, Cambridge, New York, Cape Town: Cambridge University Press, 2002.

DIAS, D. L. A entrevista mediada por computadores: uma proposta de análise da configuração de gênero (resumo). In: DUTRA, Deise Prina et al. (Org.). $V I$ Congresso Brasileiro de Lingüística Aplicada: A Linguagem como Prática Social - Programa \& Resumos. Belo Horizonte: FALE/UFMG, 2001. p.141.

DUTRA, D. P. et al. (Org.). VI Congresso Brasileiro de Lingüística Aplicada: A Linguagem como Prática Social-Programa \& Resumos. Belo Horizonte: FALE/UFMG, 2001. p. 141.

DUTRA, D. P., MELLO, H. R. e PAIVA, V. L. M. O. (Org.). VI Congresso Brasileiro de Lingüística Aplicada - A Linguagem como Prática Social - 7 a 11 de outubro de 2001 - Programa \& Resumos. Belo Horizonte, FALE/ UFMG, 2001. 262 p.

HODGES, R. E. (Ed.). What is Literacy? - Select Definitions and Essays from The Literacy Dictionary: The vocabulary of reading and writing. Newark, DE: IRA, 1999. p.19.

KAMIL, M. L. INTRATOR, S. M.; KIM, H. S. The Effects of Other Technologies on Literacy and Literacy Learning. In: KAMIL, M.L. et al. In: Handbook of Reading Research, v. III. Mahwah, NJ: LEA, 2000. p.771-788.

LEU, Jr. D. J. Literacy and Technology: Deictic Consequences for Literacy Education in an Information Age. In: KAMIL, M. L. et al. (Ed.). Handbook of Reading Research, v. III. Mahwah, New Jersey, London: Lawrence Erlbaum Associates Publishers, 2000. p.743-770. 
LEU, Jr. D. J. The New Literacies: Research on Reading Instruction with the Internet. In: FARSTRUP, A. E.; SAMUELS S. J. (Ed.). What Research has to Say About Reading Instruction. Newark, Delaware: IRA, 2002. p.310-336.

SEMALI, L. Crossing the Information Highway: The Web of Meanings and Bias in Global Media [on line]. December 2002. [cited 03/01/2003]. Available from World Wide Web: <http://www.readingonline.org/newliteracies/semali3/.

SILVA, J. P.; SIMON, M. L. M. (Coord.). IV Congresso Nacional de Lingüistica e Filologia - Rio de Janeiro, UERJ, 28 de agosto a 01 de setembro de 2000 - Livro de Resumos e Programação. Rio de Janeiro: Círculo Fluminense de Estudos Filológicos e Lingüísticos, Instituto de Letras da UERJ, Academia Brasileira de Filologia, Centro Filológico Clóvis Monteiro, 2000. 92 p.

SOARES, M. E.; ARAGÃO, M. S. S. (Org.). XVIIIJornada de Estudos Lingüisticos. Salvador, UFBA, 3 a 6 de setembro de 2000 - Programa \& Resumos. Salvador: GELNE, UFBA/UFC, 2000. 265 p.

SOARES, M. E.; ARAGÃO, M. S. S. (Org.). II Congresso Internacional da ABRALIN (Associação Brasileira de Lingüistica), 13 a 16 de março de 2001 - Programa \& Resumos. Fortaleza: UFC/ABRALIN, 2001. 382p. 